\title{
Similar but not the same: Application of EEG frontal alpha asymmetry to game research
}

\author{
Michał Leszek Mycka, Adam Czajka \\ Poznań University of Economics and Business | Collegium Da Vinci, Poznań \\ michal@mycka.pl | ORCID: 0000-0003-4157-6762 \\ adam.czajka@cdv.pl
}

\begin{abstract}
In this study we investigate the efficacy of frontal alpha asymmetry (FAA) to differentiate between successful and unsuccessful games. Participants $(N=27)$ came to the lab setting on two occasions, playing one commercially available game on each visit while being measured by electroencephalography (EEG). The results revealed that FAA can be successfully used to differentiate between games, even when the differences between them are too small to be captured by self-report methods. The differences in the elicited FAA in two games correlated with the differences in player behavior measured immediately after the game sessions. However, FAA was not related to the enjoyment reported by the players.
\end{abstract}

Keywords: electroencephalography, frontal alpha asymmetry, player experience, video games, engagement 



\section{Introduction}

Video games absorb more and more of people's spare time competing with other common activities such as reading books, listening to music, watching movies or playing sports. According to a recent report of the Entertainment Software Association (2016) the value of the US game industry in 2015 was about 23.5 billion dollars. This gives rise to increased competition among game developers to grab and keep the players' attention by delivering more and more innovative products. However, with the accompanying increase of production costs, many developers decide to balance between the innovation and familiarity in their games to avoid the potential loss associated with the commercial failure of the game. Large studios, such as Electronic Arts or Ubisoft, focus on developing sequels of well-known game series, while some groups of smaller studios try to reproduce game experiences similar to their successful competitors. This creates the need to seek more precise tools to pre-test the player reactions before the official publication of the game. In these circumstances there is a growing interest in using neurophysiological methods such as electroencephalography (EEG). Measuring brain waves during gameplay with EEG gives an opportunity to record very small changes between similar stimuli which may have a substantial effect on player preferences. Moreover, EEG has an advantage over self-report methods, as it offers objective and continuous measurement of player experience.

Using EEG to investigate player experiences has received some attention in recent years. Existing game research utilizing EEG has focused on measuring players' responses to different level designs (Nacke, Stellmach, \& Lindley, 2010), measuring mental workload (He, Yuan, Yang, Sheikholeslami, \& He, 2008) or searching for brain activity patterns which may be used in brain-computer interfaces (Berta, Bellotti, De Gloria, Pranantha, \& Schatten, 2013). Even though some researchers point out that EEG metrics based on hemisphere asymmetries can be used in game research (Kivikangas et al., 2011), this possibility has not yet been fully explored.

\subsection{Frontal alpha asymmetry}

The general body of research suggests that behaviour is organized by two complementary systems. One, responsible for approach-tendencies 
to stimuli, is related to greater EEG alpha activity over the left prefrontal cortex (L). The other one is associated with withdrawal-tendencies from stimuli and reflected in greater EEG alpha activity over the right prefrontal cortex (R) (Davidson, 1984, 1993; Sutton \& Davidson, 1997; for a review see: Coan \& Allen, 2004). Both measures are collected simultaneously to create the ratio score $(\mathrm{R}-\mathrm{L}) /(\mathrm{R}+\mathrm{L})$. Since the power in the alpha band is inversely related to the activity of the hemispheres (Pizzagalli, 2007), positive values of the ratio denote greater activation of the left hemisphere and relatively greater approach-tendency. The frontal alpha asymmetry index is useful for differentiating video advertisements (Ohme, Reykowska, Wiener, \& Choromanska, 2010) and psychopathological states (Stewart, Coan, Towers, \& Allen, 2011).

Even though frontal alpha asymmetry seems to reflect behavioural tendencies, there is still an ongoing discussion on how it relates to the emotional valence of the stimuli (for a review see: Spielberg, Stewart, Levin, Miller, \& Heller, 2008). The popular view is that experiencing positive emotions leads to approach behaviour, and experiencing negative ones leads to withdrawal from the stimuli (Heller, 1990; Davidson, 2004). This holds true for positive emotions such as happiness or surprise, and for negative emotions such as sadness, fear or disgust. However, anger as a negative emotion still leads to the approach to the stimuli and falls into the same group as surprise and happiness (Harmon-Jones, 2004).

\subsection{Current research}

In the present study we want to explore the potential use of frontal alpha asymmetry as a metric which differentiates between potentially successful and unsuccessful games. We hypothesize that this asymmetry will be positively related to the players' tendency to continue the game. Moreover, as games elicit both negatively and positively valenced emotional states (Jennett et al., 2008), we want to check if there is an association between frontal alpha asymmetry and enjoyment coming from gameplay. In order to answer the above questions we compare two commercially available games. We based our choice of games on two criteria. In order to get a clear indication of the games' success, they needed to vary on the grounds of available aggregate user scores. Despite this difference, we wanted them to be as similar as possible in terms of genre, game mechanics, controls 
and setting. The criteria put in this way set a high precision threshold for the measurement methods used in the study. According to the review by Boyle, Connolly, Hainey, \& Boyle (2012), self-report methods are still the most popular method to measure player experience. Therefore, beside EEG measurement we decided to use one of the popular questionnaires together with a single measure of player engagement for the purpose of comparison.

\section{Method}

\subsection{Measures}

\subsubsection{Electroencephalograph}

A B-Alert EEG wireless headset (Berka et al., 2004, 2007) was used for all recordings. The signal was recorded with 9 EEG referential channels (Fz, $\mathrm{F}_{3}, \mathrm{~F}_{4}, \mathrm{Cz}_{2} \mathrm{C}_{3}, \mathrm{C}_{4}, \mathrm{PO}_{2}, \mathrm{P}_{3}, \mathrm{P}_{4}$ ), placed according to the $10-20$ system (Jasper, 1958) and referenced to the linked mastoids. The data was collected with a sampling rate of $256 \mathrm{~Hz}$. Impedances during all recordings were kept below $40 \mathrm{k} \Omega$ - as recommended by the equipment manufacturer. The signal was automatically decontaminated (Berka et al., 2007) from the known artifacts such as eye movements, muscle tension, or those associated with the movement of the electrodes and the saturation of the amplifier. In order to obtain a decontaminated signal the subjects had to perform a standardized baseline procedure comprising three tasks: eyes closed for 5 minutes, eyes open for 5 minutes, 3-Choice Vigilance Task.

\subsubsection{Video recording}

Two cameras were used. One camera (Logitech C920) was used to record the participants' movements to search for EEG epochs prone to movement artifacts. The other camera (Microsoft LifeCam HD-300o) was used to record the game-session to later mark its beginning and ending on EEG recordings.

\subsubsection{Play-time estimation}

For a single measure of player engagement we decided to check the elicited time distortion. This characteristic of engaging experience often 
reported by the players (Poels, de Kort, \& IJsselsteijn, 2008) is defined by the overestimation or underestimation of the time spent in game. Time distortion differentiates between levels of game engagement, but only when the participants know from the beginning that they will have to make such an estimate after the play session (Sanders \& Cairns, 2010). The participants were asked to mark the time spent in the game by entering their estimate in the form of one value, without entering ranges.

\subsubsection{Reported engagement}

Based on a review by Nordin, Denisova, \& Cairns (2014), we decided to use the Immersion Experience Questionnaire (IEQ) constructed by Jennett et al. (2008) in a validated Polish version (Strojny \& Strojny, 2014). The questionnaire consisted of 27 items on a 5-point scale. After reverse scoring of negative items, all items were summed up.

\subsubsection{Reported enjoyment}

This 4-item scale was answered on the 5-point Likert type scale consisting of questions like "This game was fun to play". The one negative item was reverse scored and then all items were added together with a Cronbach's $a=.90$.

\subsubsection{Subsequent play behaviour}

Similarly to a procedure by Ryan, Rigby, \& Przybylski (2006), this dichotomous variable was measured after a game-session in a freechoice format. Participants could choose whether to continue the game, read one of the popular paper-version game magazines or freely use their (smart)phones. The cases where the participant remained in the game for more than one minute during a 10-minute period were classified as continuation, and the other cases were classified as discontinuation. The one minute threshold was used because during the pilot study some subjects came back to the computer only in order to check their score and quit the game.

\subsection{Games}

Two commercially available PC games from the tower-defense genre were selected: Kingdom Rush (2014) and 300 Dwarves (2013). Both games had 
similar game mechanics, controls, range of options offered to players (e.g. tower upgrades, special powers), both were set in a fantasy world with a similar plot, and both offered a tutorial presented in a similar way during the first level of the game. Despite this, on www.steampowered.com Kingdom Rush was near the top of the user rankings (96\%) and 300 Dwarves was near the bottom (52\%).

\subsection{Participants}

The data was recorded for 27 males, aged 20 to $39(M=25.7, S D=4.46)$. 2 participants were left-handed. 6 participants were wearing glasses or contact lenses. Each participant declared that they played video games at least two times a week. 1 participant had played 300 Dwarves and 3 other participants had played Kingdom Rush before. Prior to the enrollment the participants were screened using self-report scales to exclude those suffering from neurological and psychiatric disorders. Other exclusion criteria included head injuries within the last 5 years and sleep disorders. To exclude other known interferences which might affect EEG data, the participants were asked to abstain from alcohol 24 hours before the scheduled visit. The participants were also prompted to limit the consumption of caffeine on the day of the visit and to abstain from cigarettes for at least 1 hour before the visit.

\subsection{Procedure}

The experiments were run during 3 consecutive weeks, with the first session starting at $8 \mathrm{a} . \mathrm{m}$. and the last session starting at 6 p.m. each day of the week. Each session lasted approximately 2 hours 15 minutes. All the experiments were carried out in artificial lighting conditions, in the absence of external sources of light and with similar temperature prevailing in the laboratory room (20 degrees Celsius +/- 1 degree). All participants came to the lab setting on two occasions, 2 to 15 days apart, playing a different game on each visit, except for 2 participants who missed session two. Based on a random assignment, 14 of the participants played Kingdom Rush first, and the other 13 began with 300 Dwarves.

On the first visit, after the description of the experimental procedure, each participant was asked to read and sign their informed consent form. 
Next, the participants were prepared for the EEG recording. After attaching the EEG electrodes and checking impedances they were asked to do the baseline tasks. Then they were seated in an office chair which was adjusted according to their individual height. Next, the cameras were set in place. Then the participants played one of the games described above. They did not know exactly what game they were about to play; they were only informed that every time the game was selected from a pool of more than a dozen games chosen for the study. The participants were also told that the length of time they were to play each game was randomly assigned on each visit and that they would be estimating it after play session. In truth, this time period was fixed at 23 minutes for all game sessions on both visits. After the designated time had passed, the participants were prompted to pause the game. After the play session they filled out a paper form consisting of play-time estimation, IEQ and enjoyment scale. Afterwards, all electrodes were removed, the cameras were shut off, and the participants were told that this part of experiment was finished but they had to wait for 10 minutes for the experimenter to check the quality of the gathered data. During that time the participants were given a choice to read one of a popular gaming magazines, use their (smart)phones or continue to play the game. When the time had passed, the participants were scheduled for the second visit.

The second session was similar to the first one, except for the game played. After the second session the participants were debriefed and received compensation (a cinema ticket) for their participation in the study.

\section{Results}

\subsection{Preliminary analyses}

\subsubsection{EEG data pre-processing}

The EEG data acquired from one participant on both sessions was excluded from further analyses due to strong artifact contamination. For the rest of the participants the EEG epochs, lasting 2 seconds, were divided into three 1-second segments with an overlap of $50 \%$. Data segments were 
windowed using the Kaiser function. Then, each segment power spectra were computed with the use of Fast Fourier Transform (FFT).

Studies on player experience commonly use fixed frequency bands for alpha rhythm (e.g. 8-14 Hz) for all subjects (e.g. Nacke et al., 2010; Berta et al., 2013). It has been found that individually defined frequencies give a more accurate estimate of neural activity (Klimesch, 1999; Klimesch, Schack, \& Sauseng, 2005). Inter-individual variability observed in alpha frequency shows that with fixed frequency window there is a possibility to mistakenly include activity from neighboring frequencies (e.g. theta) in the alpha window. In view of the above, alpha frequency was defined individually per subject, similarly to the study by Doppelmayr, Klimesch, Pachinger, \& Ripper (1998). Peak alpha frequency (PAF) was computed by averaging the peak frequency measured in the 8-13 Hz frequency bins at $\mathrm{POz}$ electrode during the eyes-closed period. For each participant individual alpha frequency (IAF) was defined as a range (PAF - 4: $\mathrm{PAF}+2)$. The mean natural-logged power value of IAF measured at $F_{3}$ and $F_{4}$ electrodes was used to compute the frontal alpha asymmetry index (FAA) using the following formula: $\left(\mathrm{F}_{4}-\mathrm{F}_{3}\right) /\left(\mathrm{F}_{4}+\mathrm{F}_{3}\right)$. For the purpose of statistical analyses the average value of FAA was computed for each 23 minute-long game session.

\subsubsection{Data treatment}

The data from two participants who missed their second session was excluded from further analyses. Next, explorative data analysis was conducted to check if the values of play-time estimation, IEQ, enjoyment and FAA deviated from normal distribution. Shapiro-Wilk test for normality indicated that play-time estimation for 300 Dwarves deviated significantly from the normal distribution $(p<.05)$. Therefore, further analyses used for that variable were non-parametric.

The final sample size used in the analyses of self-report measures was 25 participants. For EEG analyses the sample size was 24 participants.

\subsection{Primary analyses}

To verify which of the games would be preferred more by the participants we conducted analysis on subsequent play behaviour and reported enjoyment. Based on McNemar's test with the continuity correction, 
the number of participants who decided to continue playing was significantly different between two games $\left(\chi^{2}=5.818, d f=1, p=.016\right)$. The participants were more likely to continue playing Kingdom Rush than 300 Dwarves (see table 1). The dependent-samples t-test was used to check the differences in reported enjoyment. Participants enjoyed Kingdom Rush $(M=15.52, S D=3.62)$ more than 300 Dwarves $(M=12.32$, $S D=3.70), t(24)=3.09, p=.005$.

Table 1. Frequencies of players' decisions to continue the games during the free-choice period.

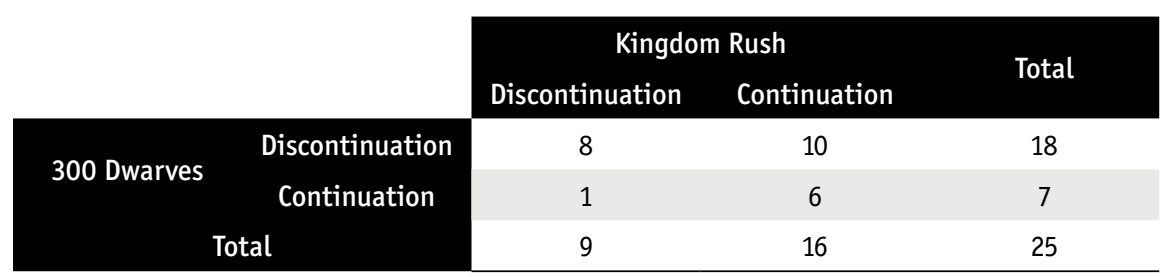

In order to test which of the measures differentiated both games, statistical tests were ran on play-time estimate, IEQ and FAA scores. The Wilcoxon signed-rank test indicated that there was no statistically significant difference between the games in the time estimated by participants $(p=.200)$. The difference in the IEQ scores was also non-significant as indicated by the dependent-samples t-test $(p=.213)$. However, the dependent samples t-test indicated that Kingdom Rush elicited higher FAA values $(M=.0058, S D=.0099)$ than 300 Dwarves $(M=-.0042, S D=.0125), t(23)=4,24, p<.001$.

Further, we examined if the differences in enjoyment and subsequent play behaviour in both games were associated with the differences identified in the FAA score. First, the 300 Dwarves scores were subtracted from Kingdom Rush scores on subsequent play behaviour, enjoyment and FAA. Next, the obtained differential scores were correlated. Based on the results of Pearson correlation, there was no statistically significant association between reported enjoyment and FAA $(p=.594)$. Before the last analysis, due to the negative result obtained by one participant on the subsequent play behaviour differential score, we multiplied his results by -1 to keep the dichotomous character of the variable. The relationship 
between subsequent play behaviour and FAA was found to be moderate as indicated by the point-biserial correlation $(r p b=.462, p=.023)$. Based on $r$-squared value, the FAA explained $21.3 \%$ of variance in the player behaviour.

\section{Discussion}

In this comparative study of two similar games we verified the usefulness of frontal alpha asymmetry as a measure of game success and as an indicator of the players' behavioural tendencies. The two tested games elicited different approach-withdrawal tendencies among participants. Kingdom Rush as a more successful game elicited a higher approach tendency than the less successful 300 Dwarves. This result corresponds with the earlier findings in the advertisement research, where more successful advertisements elicited relatively higher left hemisphere activation (Ohme et al., 2010). As further evidence, the difference in elicited FAA between the games was related directly to the differences in subsequent behaviour of the players. This result is consistent with the general prediction that greater approach-tendencies are reflected in the higher activation of the left hemisphere (Sutton \& Davidson, 1997).

Although the FAA turned out to differentiate between both games and correlate with the subsequent behaviour of the participants, it was not related to the reported difference in enjoyment. The popular view is that people withdraw from aversive stimuli and approach positive ones. Thus, a higher approach tendency reflected in relatively higher FAA should be accompanied by higher enjoyment reported. However, this was not supported by our results. Our findings provide empirical support for the alternative hypothesis that emotional valence of the stimuli is not reflected by the FAA. Although experiencing positive states leads to approach behaviour, the negatively valenced ones do not always lead to withdrawal from the stimuli. The finding that FAA was not related to reported enjoyment suggests that motivational and emotional dimensions should not be confounded when interpreting FAA results in player experience research.

Overall, our study provides support for using frontal alpha asymmetry as a reliable and precise indicator of game success and player behaviour. 
Those characteristics of FAA are especially important for researchers interested in analyzing games from the psychophysiological perspective, and for game developers who have a hard time making their products succeed in the crowded game market. More generally, using psychophysiological measures has allowed us to capture small but crucial differences between similar games. It would be very difficult to obtain analogous results using the self-report methods. Apart from those promising results, our research does not provide a finite and fully confident solution. There is still need for further research which should focus on long-term player behaviour and on other game genres as they put different cognitive demands on players.

\section{Acknowledgements}

This work was partially funded by the Faculty of Computing and Visual Communication, Collegium Da Vinci.

\section{References}

Berka, C., Izzetoglu, K., Bunce, S., Onaral, B., Pourrezaei, K., \& Chance, B. (2004). Real-Time Analysis of EEG Indexes of Alertness, Cognition, and Memory Acquired With a Wireless EEG Headset. International Journal of Human-Computer Interaction, 17(2), 211-227.

Berka, C., Levendowski, D. J., Lumicao, M. N., Yau, A., Davis, G., Zivkovic, V. T., Craven, P. L. (2007). EEG correlates of task engagement and mental workload in vigilance, learning, and memory tasks. Aviation Space and Environmental Medicine, 78 (5 II).

Berta, R., Bellotti, F., De Gloria, A., Pranantha, D., \& Schatten, C. (2013). Electroencephalogram and physiological signal analysis for assessing flow in games. IEEE Transactions on Computational Intelligence and AI in Games, 5(2), 164-175.

Boyle, E. A., Connolly, T. M., Hainey, T., \& Boyle, J. M. (2012). Engagement in digital entertainment games: A systematic review. Computers in Human Behavior, 28(3), 771-780. 
Coan, J. A., \& Allen, J. J. B. (2004). Frontal EEG asymmetry as a moderator and mediator of emotion. Biological Psychology, 67(1-2), 7-49.

Davidson, R. J. (1984). Affect, cognition, and hemispheric specialization. In C. E. Izard, J. Kagan, \& R. B. Zajonc (Eds.), Emotion, Cognition, and Behavior (pp. 320-365). Cambridge University Press.

Davidson, R. J. (1993). Cerebral Asymmetry and Emotion: Conceptual and Methodological Conundrums. Cognition and Emotion, 7(1), 115-138.

Davidson, R. J. (2004). What does the prefrontal cortex "do" in affect: Perspectives on frontal EEG asymmetry research. Biological Psychology, 67(1-2), 219-233.

Doppelmayr, M., Klimesch, W., Pachinger, T., \& Ripper, B. (1998). Individual differences in brain dynamics: important implications for the calculation of event-related band power. Biological Cybernetics, 79(1), 49-57. Entertainment Software Assotiation. (2016). 2016 Essential Facts About the Computer and Video Game Industry. Retrieved from http://www.theesa. com/wp-content/uploads/2016/04/Essential-Facts-2016.pdf.

Harmon-Jones, E. (2004). On the relationship of frontal brain activity and anger: Examining the role of attitude toward anger. Cognition E Emotion, 18(3), 337-361.

He, E. J., Yuan, H., Yang, L., Sheikholeslami, C., \& He, B. (2008). EEG spatio-spectral mapping during video game play. In 5 th Int. Conference on Information Technology and Applications in Biomedicine, ITAB 2008 in conjunction with 2nd Int. Symposium and Summer School on Biomedical and Health Engineering, IS3BHE 2008 (pp. 346-348).

Heller, W. (1990). The neuropsychology of emotion: Developmental patterns and implications for psychopathology. In N. L. Stein, B. Leventhal, \& T. Trabasso (Eds.), Psychological and biological approaches to emotion (pp. 167-211). Lawrence Erlbaum Associates.

Jasper, H. H. (1958). Report of the committee on methods of clinical examination in electroencephalography. Electroencephalography and Clinical Neurophysiology, 10(2), 370-375.

Jennett, C., Cox, A. L., Cairns, P., Dhoparee, S., Epps, A., Tijs, T., \& Walton, A. (2008). Measuring and defining the experience of immersion in games. International Journal of Human Computer Studies, 66(9), 641-661. Kivikangas, J. M., Chanel, G., Cowley, B., Ekman, I., Salminen, M., Järvelä,S., \& Ravaja, N. (2011). A review of the use of psychophysiological 
methods in game research. Journal of Gaming E Virtual Worlds, 3(3), 181-199.

Klimesch, W. (1999). EEG alpha and theta oscillations reflect cognitive and memory performance: A review and analysis. Brain Research Reviews, 29(2-3), 169-195.

Klimesch, W., Schack, B., \& Sauseng, P. (2005). The functional significance of theta and upper alpha oscillations. Experimental Psychology, 52(2), 99-108.

Nacke, L. E., Stellmach, S., \& Lindley, C. A. (2010). Electroencephalographic assessment of player experience: A pilot study in affective ludology. Simulation \& Gaming, 42 (5), 632-655.

Nordin, A. I., Denisova, A., \& Cairns, P. (2014). Too Many Questionnaires: Measuring Player Experience Whilst Playing Digital Games. In Seventh York Doctoral Symposium on Computer Science \& Electronics (pp. 69-75).

Ohme, R., Reykowska, D., Wiener, D., \& Choromanska, A. (2010). Application of frontal EEG asymmetry to advertising research. Journal of Economic Psychology, 31(5), 785-793.

Pizzagalli, D. A. (2007). Electroencephalography and High-Density Electrophysiological Source Localization. In: J. T. Cacioppo, L. G. Tassinary, \& G. G. Berntson (Eds.), Handbook of Psychophysiology (Third Edit, pp. 56-84). Cambridge University Press.

Poels, K., de Kort, Y. A. W., \& IJsselsteijn, W. A. (2008). Identification and Validation of Post-Game Experiences. In CHI Conference.

Ryan, R. M., Rigby, C. S., \& Przybylski, A. (2006). The motivational pull of video games: A self-determination theory approach. Motivation and Emotion, 30(4), 347-363.

Sanders, T., \& Cairns, P. (2010). Time perception, immersion and music in videogames. In Proceedings of the 24th BCS Interaction Specialist Group Conference (pp. 160-167).

Spielberg, J. M., Stewart, J. L., Levin, R. L., Miller, G. A., \& Heller, W. (2008). Prefrontal Cortex, Emotion, and Approach/Withdrawal Motivation. Social and Personality Psychology Compass, 2(1), 135-153.

Stewart, J. L., Coan, J. A., Towers, D. N., \& Allen, J. J. B. (2011). Frontal EEG asymmetry during emotional challenge differentiates individuals with and without lifetime major depressive disorder. Journal of Affective Disorders, 129(1-3), 167-174. 
Strojny, P., \& Strojny, A. (2014). Kwestionariusz immersji - polska adaptacja i empiryczna weryfikacja narzędzia / The Immersion Questionnaire - Polish adaptation. Homo Ludens, 1(6), 171-185.

Sutton, S. K., \& Davidson, R. J. (1997). Prefrontal brain asymmetry: A biological substrate of the behavioral approach and inhibition systems. Psychological Science, 8(3), 204-210.

Michat Leszek Mycka M.A. - PhD student at Faculty of Managment, Poznań University of Economics and Business, Poznań. Portions of this research were done while the author was a researcher at Setapp sp. z o.o. and at emotions $L A B$, Collegium Da Vinci, Poznań

Adam Czajka PhD - Faculty of Computing and Visual Communication, Collegium Da Vinci, Poznań

\title{
Podobne, ale nie tożsame: zastosowanie asymetrii czołowej, mierzonej w paśmie alfa, w badaniach gier
}

\begin{abstract}
Abstrakt: W ramach badania weryfikowaliśmy skuteczność asymetrii czołowej mierzonej w paśmie alfa (FAA) w różnicowaniu gier, które odniosły sukces rynkowy, i tych, które takiego sukcesu nie odniosły. Uczestnicy $(N=27)$ odbywali dwie wizyty w laboratorium, za każdym razem grając w jedną dostępną komercyjnie grę. W trakcie każdego z badań dokonywano pomiaru fal mózgowych uczestników za pomocą elektroencefalografii (EEG). Wyniki wykazały, że FAA można z powodzeniem stosować do rozróżniania pomiędzy grami, nawet jeśli różnice pomiędzy nimi są zbyt małe, aby zostały uchwycone metodami samoopisowymi. Różnice mierzone w FAA podczas dwóch rozgrywek były skorelowane z różnicami w preferencjach graczy. Jednak wskaźnik FAA nie był związany z deklarowaną przyjemnością z rozgrywki.
\end{abstract}

Słowa kluczowe: encefalografia, asymetria czołowa, doświadczenie gracza, gry wideo, zaangażowanie 